\title{
Chemico-Vector and Mechanochemico-Vector Properties of Polarized Glass-Ceramic Silicophosphate of Narpsio
}

\author{
Satoshi NAKAMURA, ${ }^{*}$ Masato KONNO, ${ }^{* * *}$ Keiichi KATAYAMA** and Kimihiro YAMASHITA* \\ *Institute of Biomaterials and Bioengineering, Tokyo Medical and Dental University, 2-3-10, Kanda-Surugadai, Chiyoda-ku, Tokyo $101-0062$ \\ **School of Engineering, Tokai University, 1117, Kita-Kaname, Hiratsuka-shi, Kanagawa 259-1292
}

\author{
ケイリン酸塩結晶化ガラス Narpsio のケミコベクトル及びメカノケミコベクトル特性 \\ 中村 聡* . 今野正人*,** . 片山恵一** . 山下仁大* \\ *東京医科歯科大学生体材料工学研究所, 101-0062 東京都千代田区神田駿河台 2-3-10 \\ **東海大学工学部, 259-1292 神奈川県平塚市北金目 1117
}

\begin{abstract}
Glass-ceramics of $\mathrm{Na}_{2} \mathrm{O}-\mathrm{R}_{2} \mathrm{O}_{3}-\mathrm{P}_{2} \mathrm{O}_{5}-\mathrm{SiO}_{2}$ (Narpsio) consist of a skeleton structure of 12-tetrahedra-membered rings and exhibit a super $\mathrm{Na}^{+}$conductivity. Glass-ceramic Narpsio was proved to be electrically polarized through highly mobile sodium ions. Narpsio also shows relatively higher solubility in water. Taking into account of the water solubility and the chemical composition, the reactivity of polarized and non-polarized glass-ceramic Narpsio in the stimulated body fluid (SBF) were investigated in relation to bioactivity. After the 6 days' immersion of SBF, hydroxyapatite microcrystals aggregated semispherically were grown on the glass-ceramic Narpsio surfaces. Although the acceleration effects were under study, the growth rate was recognized to be higher in both of the negatively and positively charged surfaces. In analogy with polarized bioglasses, we confirmed the chemico-vector effects of glass-ceramic Narpsio for biomedical purpose. Additionally, glass-ceramic Narpsio, prepared by the locally biasing crystallization method, showed unreported microstructural changes of surfaces during chemical polishing with water, depending upon the direction of a biasing field. The phenomenon was interpreted as a mechanochemico-vector effect. [Recived August 22, 2005; Accepted November 17, 2005]
\end{abstract}

Key-words : Narpsio, Polarization, Chemico-vector, Mechanochemico-vector

\section{Introduction}

$\mathrm{Na}_{5} \mathrm{YSiO}_{4}{ }^{1,2)}$-type sodium silicophosphates with the chemical formula of $\mathrm{Na}_{3+3 x-y} \mathrm{R}_{1-x} \mathrm{O}_{3} \mathrm{P}_{y} \mathrm{Si}_{3-y} \mathrm{O}_{9}$. $\quad(\mathrm{R}=$ rare earth ions) (denoted as Narpsio) are super $\mathrm{Na}^{+}$-conductors with a conductivity of $10^{-1} \mathrm{Scm}^{-1}$ at $300^{\circ} \mathrm{C}$ and an activation energy of $20 \mathrm{kJmol}^{-1} .^{3)-8)}$ Although the skeleton structure of Narpsio comprises 12- $\left(\mathrm{SiO}_{4}\right)^{4-}$ tetrahedra-membered rings, the detailed structures of the glass ceramics are controllable by their nominal composition and condition of crystallization. $^{3)-7)}$

Glass-ceramic Narpsio bears similarity in chemical formula to bioactive glasses and exhibits much higher electrical conductivity and relatively higher solubility in distillated water. Therefore, the glass-ceramic Narpsio could be electrically polarized at relatively lower temperature and intensity of the electrical field and has been supposed to be a candidate of bioabsorbable ceramic. The absorption rate was recognized to be controllable by both of its chemical composition and crystallization condition. Moreover, during crystallization process, application of electrical bias to the Narpsio could change into graded materials. In the present study, $\mathrm{Na}_{5} \mathrm{YSiO}_{4}-$ type glass-ceramic Narpsio (gc: Narpsio) has been developed as a candidate for a novel bioresorbable material. Moreover, the high ion conductivity leads us to the possibility of electrical polarization. Polarization is important in biomaterials, since we have more recently demonstrated by in vitro and in vivo tests that the charged surfaces of electrically polarized hydroxyapatite ${ }^{9), 10}$ acquired enhanced osteoconductivities. ${ }^{11)-13)}$ This study will demonstrate the electrical polarizability and in vitro biocompatibility or chemico-vector effect of gc: Narpsio.

In the development of Narpsio for a novel biomaterials, gc:
Narpsio crystallized in a local field was found to show two different mechanochemical reactions, depending upon the direction of the biasing filed. The phenomenon can be classified as a mechanochemico-vector effect, which will also be shown in this report.

\section{Experimental}

Starting glasses were prepared from reagent-grade powders of $\mathrm{Na}_{2} \mathrm{CO}_{3}, \mathrm{Y}_{2} \mathrm{O}_{3}, \mathrm{NH}_{4} \mathrm{H}_{2} \mathrm{PO}_{4}$, and $\mathrm{SiO}_{2}$ according to the literature. ${ }^{8)}$ The mixed powders of appropriate compositions were calcined at $900^{\circ} \mathrm{C}$ for $1 \mathrm{~h}$, and then, melted at $1350^{\circ} \mathrm{C}$ for $1 \mathrm{~h}$. The melts were quenched by pouring into a graphite die, and then, annealed at $500^{\circ} \mathrm{C}$ for $8 \mathrm{~h}$. Crystallization procedure was carried out according to the previous reports: $:^{5,6)}$ Some of the obtained bulk glasses were heated at an increasing rate of $\mathrm{ca} \cdot 100^{\circ} \mathrm{C} \cdot \mathrm{h}^{-1}$ to the temperature of $50^{\circ} \mathrm{C}$ above the glass transition point. After being annealed for $1 \mathrm{~h}$, the specimens were heated at $1100^{\circ} \mathrm{C}$ for $1 \mathrm{~h}$, and then, slowly cooled in a furnace to room temperature $(R T)$. The obtained glassceramic specimens were polished with diamond disks of 30,15 and $6 \mu \mathrm{m}$ in turn for further experiments. The other bulk glasses were electrically biased with $50 \mathrm{Vcm}^{-1}$ throughout during crystallization up to $900^{\circ} \mathrm{C}$ (Fig. 1), ${ }^{6)}$ then subjected to polishing after cooled down to room temperature. For observation of a mechanochemical effect, these specimens were not polarized.

Electrical polarization was undertaken on the specimens with a pair of platinum electrodes according to the previous report. ${ }^{10)}$ Platinum wire was attached to each of the electrodes. The wires insulated with $\alpha-\mathrm{Al}_{2} \mathrm{O}_{3}$ dense tubes were shielded with a stainless steel pipe. A measurement cell was placed in an electric furnace equipped with non-inductive 




Fig. 1. Narpsio glass (a) and Narpsio glass-ceramic (gc: Narpsio).

coaxial heating elements. The specimen temperature was measured by a chromel-alumel thermocouple next to the specimen. During the polarization, the specimens were heated in air at $300^{\circ} \mathrm{C}$ for $1 \mathrm{~h}$ at the polarization temperatures at a heating rate of $100^{\circ} \mathrm{C} \cdot \mathrm{h}^{-1}$ and then cooled to $R T$ at a rate of $c a$. $100^{\circ} \mathrm{C} \cdot \mathrm{h}^{-1}$. A d. c. electrical field was applied from the polarization temperature to $R T$ using a Hewlett-Packard E3620A power supply. After the electrodes were short-circuited at $R T$ for a sufficient time, the thermally stimulated current (TSC) measurements were carried out in air from $R T$ to $750^{\circ} \mathrm{C}$ at a constant heating rate of $2.0^{\circ} \mathrm{C} \cdot \mathrm{min}^{-1}$. The TSC method ${ }^{14)}$ involves the polarization of the samples by a static field at high temperature. The sample is then cooled to a temperature at which the external field is removed and heated at a constant rate. A current corresponding to dipole relaxation is recorded as a function of time and temperature. The depolarization current was measured with a Hewlett-Packard 4140B pA meter. All of the instruments were networked with an IEEE488 interface and controlled and monitored with a personal computer. The data were later analyzed with the appropriate software.

The reactivities on the surfaces of the polarized and the nonpolarized gc: Narpsio were evaluated by immersing in simulated body fluid (SBF). The SBF with ion concentrations nearly equal to those of human blood plasma was prepared using the technique described by Kokubo ${ }^{15)}$ for precipitation of bonelike apatite. Specimens were immersed in $10 \mathrm{~cm}^{3}$ of SBF in plastic bottles at $37^{\circ} \mathrm{C}$ up to $6 \mathrm{~d}$. The immersed samples were then removed from the SBF solutions and washed with distilled-deionized water. The obtained specimens were dried at $R T$ for microstructural observations.

For the study of mechanochemical property, water-polished surfaces of polarized non-polarized gc: Narpsios as well as local-filed biased gc: Narpsio's (Fig. 1) were subjected to SEM observation. Polishing for SEM was carried out using diamond disk of 30 down to $6 \mu \mathrm{m}$ in diameter with distilled water.

\subsection{Characterization}

\section{Results and discussion}

The obtained glass-ceramics were white opaque and had homogeneous appearance without any inclusion. The crystalline phase was verified to be $\mathrm{Na}_{5} \mathrm{YSiO}_{4}$-type single-phase by XRD analysis (Fig. 2). All the glass-ceramic specimens, whether or not crystallized under biasing field, were identified as a $\mathrm{Na}_{5} \mathrm{YSiO}_{4}$-type single phase in an XRD analytical accuracy.

The TSC curve (Fig. 3) of the polarized gc: Narpsio increased at $c a .100^{\circ} \mathrm{C}$ and showed noticeable 4 peaks at $c a .172$, $350,451,620$ and $730^{\circ} \mathrm{C}$. The polarization charge calculated from numerical integration of the TSC spectrum was 55 $\mathrm{mCcm}^{-1}$. According to the previous reports, ${ }^{4,5)}$ the ionic conduction through grain boundary was detectable above $195^{\circ} \mathrm{C}$.

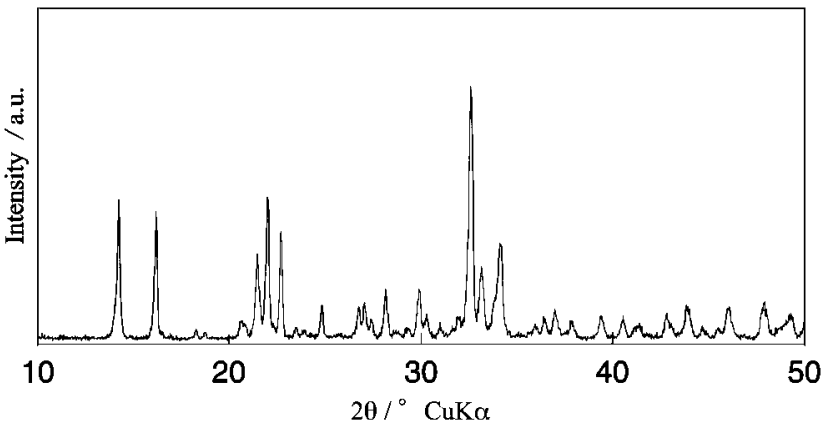

Fig. 2. XRD pattern of gc: Narpsio.

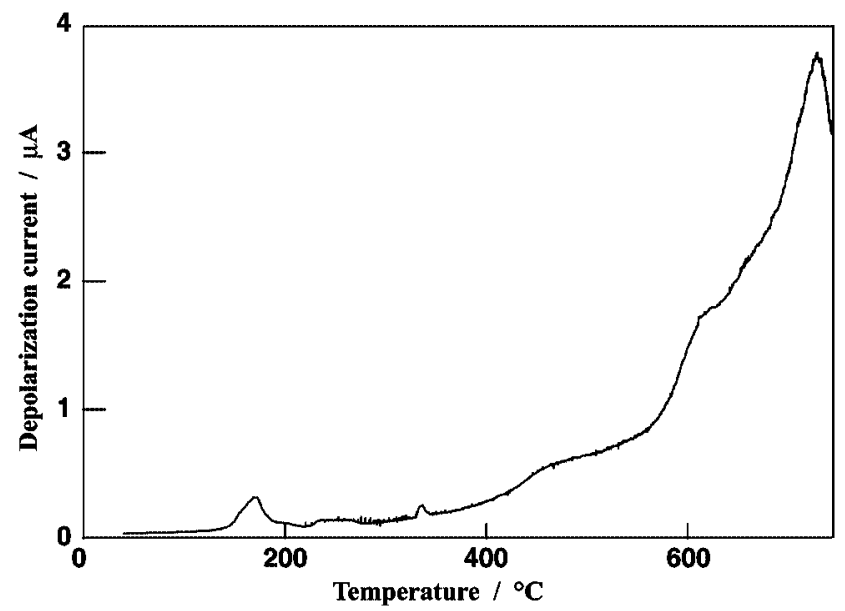

Fig. 3. TSC spectrum of gc: Narpsio electrically polarized at $300^{\circ} \mathrm{C}$.

The first-peak temperature fairly agreeing with the characteristic temperature about conduction was interpreted to be the threshold temperature of transport length expanding of sodium ions. The third $\left(451^{\circ} \mathrm{C}\right)$ and the fourth $\left(620^{\circ} \mathrm{C}\right)$ temperatures giving peaks coincided with the glass transition and the crystallization temperatures reported in the literatures, ${ }^{4), 5)}$ respectively. The fifth and largest peak was attributed to the relaxation of the $\mathrm{Na}^{+}$ions shifted by the polarization treatment. Although the phenomena corresponded to the second peak at $350^{\circ} \mathrm{C}$ was not yet completely analyzed, the peak was attributable to structural changes and/or relaxations caused by thermal stimulation. The stored charge was recognized to be huge, compared to the polarized hydroxyapatite ceramics ${ }^{16)}$ and bioactive glasses, ${ }^{17)}$ and was attributed to the high electrical conductivity of gc: Narpsio. Taking into account of mobile $\mathrm{Na}^{+}$ions in $\mathrm{Na}_{5} \mathrm{YSiO}_{4}$-type Narpsio structure, the ratio of $\mathrm{Na}^{+}$ions taking part in polarization can be estimated as 100 ppm to $0.1 \%$ of all $\mathrm{Na}^{+}$ions, including immobile ones, in the structure. This will be further mentioned to below.

\subsection{Chemicovector effect}

The negatively and positively charged surfaces of the electrically polarized gc: Narpsio's are denoted as $N$-surface and $P$-surface, respectively. The surface of the non-polarized gc: Narpsio is denoted as 0 -surface.

Morphologies of overgrown crystals on gc: Narpsio surfaces after the immersion in SBF for $6 \mathrm{~d}$ are shown in SEM photographs (Fig. 4). The XRD patterns of the immersed gc: Narpsio surfaces including a small 002 peak and a broad peak assignable to 211,112 and 300 reflections of hydroxyapatite. 

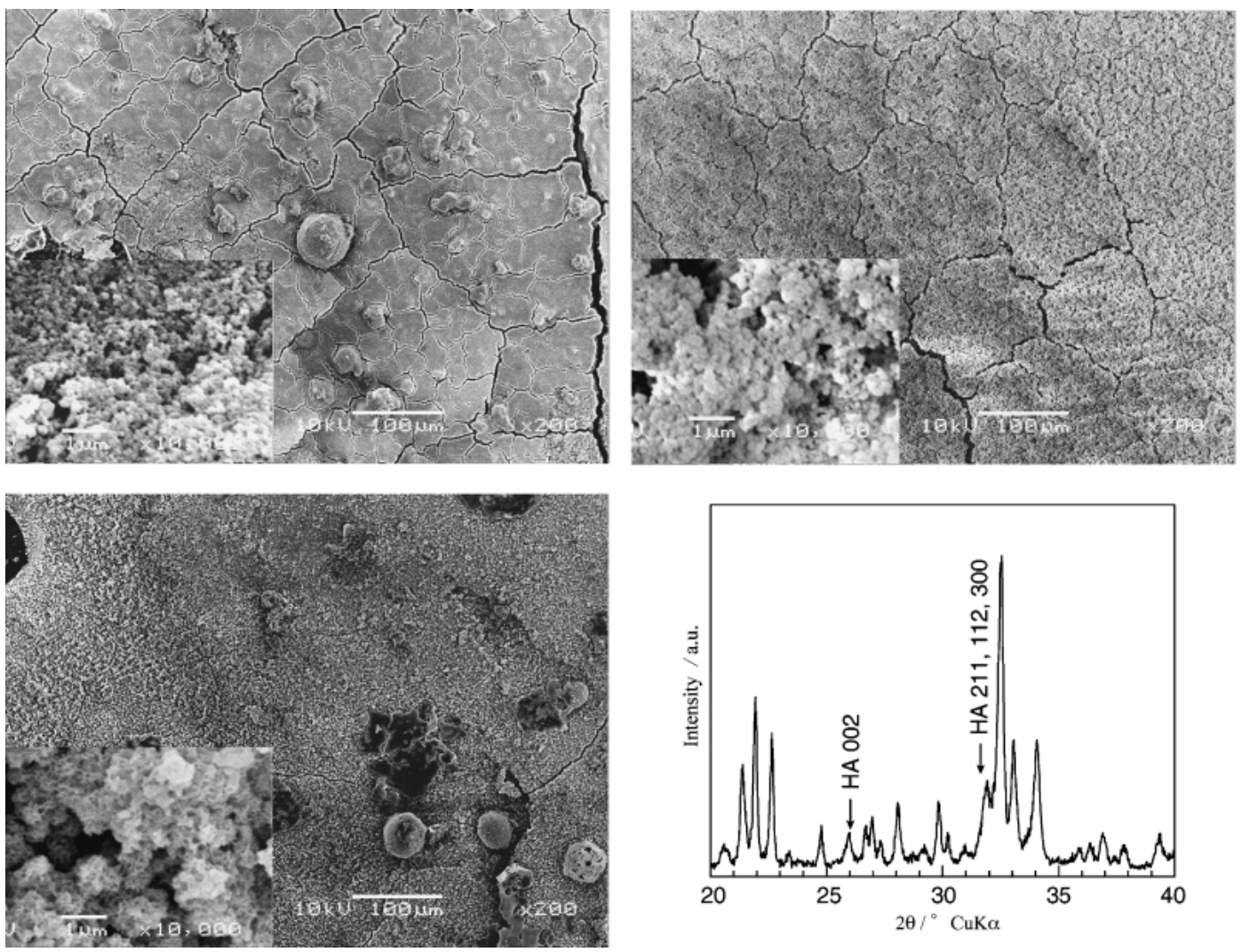

Fig. 4. Morphologies of overgrown crystals on gc: Narpsio after immersed in SBF $6 \mathrm{~d} ; N$-surfaces (upper left), $P$-surfaces (upper right), and 0 -surfaces (lower left). Scale bars indicate $100 \mu \mathrm{m}$. Insets of highly magnified photographs (Scale bars indicate $1 \mu \mathrm{m}$ ) showed that overgrown layers consisted of nanosized crystals. XRD pattern (lower right) of overgrown layer on $N$-surface.

The overgrown crystals were densely aggregated and formed layer structures with cracks, while the thickness was varied in accordance with surface charges. The thickness was not able to be statistically compared because of wide deviations of estimated values from SEM observation. The unclearness was attribute to the high solubility of the gc: Narpsio. The concealment of surface charge effects by high solubility was reported in the case of bioactive glass of 45S5 type. ${ }^{18)}$

In the $N$-surfaces, the layered overgrown deposits were observed with semispherical grains of $10-50 \mu \mathrm{m}$ in diameter. The thickness was recognized to indicate the highest value among the surfaces, based on an estimation from the step thickness of peeled off overgrowth layers. The grains were homogeneously sporadic on the entire layers. Based on the highly magnified SEM images, the layer consisted of 50-100 nm granular crystals. In the $P$-surfaces, the layers were remarkably porous, compared to the $\mathrm{N}$-surfaces. The diameter of the pores found in the entire layers was ranging from 0.5 to $3 \mu \mathrm{m}$. No semispherical grain was found in any views. The nanosized crystals forming the layers were similar to those in the $N$-surfaces. In the 0 -surfaces, the overgrown layers were porous, similar to the $P$-surfaces, and together with the semispherical grains, similar to the $N$-surfaces. The few number of the cracks revealed that the overgrown layers were thin. The nano-sized crystals were same as those of the other surfaces in size but different in shape. The shape of the crystals was tabular, while the dominant face and crystallographic direction were unclear. The effects of the electrical polarization were obvious in nano and micro structures of the overgrown crystals, while the influences on the growth rate of the crystals were not well delineated. The gc: Narpsio indicated the for- mability of apatite crystals in SBF regardless to the electrical polarization and gave rise to the view that gc: Narpsio was osteoconductive and capable to apply to biomedical devices.

\subsection{Mechanochemico-vectro effect}

The polarization and locally biased crystallization were phenomenologically proved to have significant influences on the mechanochemical reaction (Figs. 5a-e): Figure 5 demonstrates the different mechanochemical reactions on $N-, P$ and 0 -surfaces. Although a small amount of whiskers were projected on 0 -surface, $N$-surface promoted overall the growth of whiskers with $5 \mu \mathrm{m}$ length and $1 \mu \mathrm{m}$ diameter, and there were reversely very few whiskers on $P$-surface. Although we attempted to identify the whiskers by XRD, the analysis has not yet been completed so far because of the limited quantity of grown whiskers in the present study. Although estimation of the amount of the migrated $\mathrm{Na}^{+}$ions was difficult because of their nonuniform spatial distribution after the crystallization process with the bias, the amount must be small enough to preserve the skeleton structure of Narpsio.

The difference in whiskers growth was also observed between the parallel and perpendicular surfaces (denoted as $/ /$ - and $\perp$-surfaces, respectively) to the applied dc field of Narpsio crystallized under biasing field (Figs. 5d and e): The whiskers with 5 to $10 \mu \mathrm{m}$ in length were densely observed on $/ /$-surface, whereas there were whiskers on $\perp$-surface.

The above mentioned phenomena are presently attributed to some mechanochemical reactions of surfaces with different chemical compositions derived by polarization. As both polarization and biasing crystallization take place due to mobile $\mathrm{Na}^{+}$ions in Narpsio, polarized and biasing crystallized states are considered to correspond to local fluctuation in the 

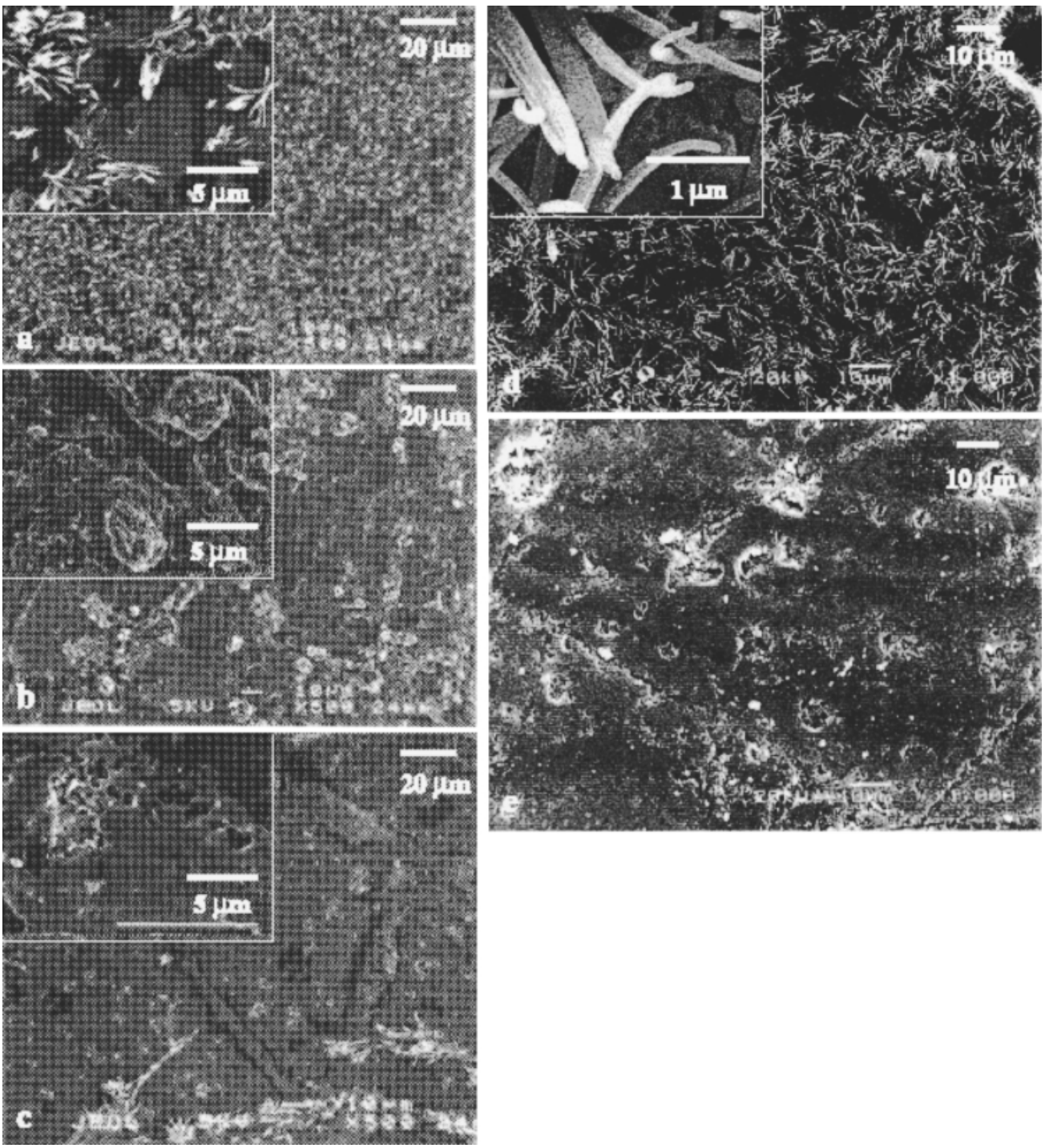

Fig. 5. Morphologies of electrically polarized surfaces (a: $N$-surfaces, and b: $P$-surfaces), non-polarized surfaces (c), and locally biased surfaces $(\mathrm{d}$ : surfaces parallel $(/ /)$ and e: surfaces perpendicular $(\perp)$ to bias direction). Insets indicate higher magnified images.

concentration of $\mathrm{Na}^{+}$ions. In the case of polarized surface, the concentration is considered as

\section{$P$-surface $>0$-surface $>N$-surface.}

Biasing crystallization is thought to give rise to the $\mathrm{Na}^{+}$concentration fluctuation as

\section{$\perp$-surface $>/ /$-surface.}

Because of the decrease of $\mathrm{Na}^{+}$ions, the structural rigidity of both $\mathrm{N}$-and //-surfaces were degraded to decomposition through a mechanochemical reaction with water during mechanical polishing. Generally, superionic conductors such as $\beta$-alumina, Nasicon and Narpsio tend to be water soluble because of mobile $\mathrm{Na}^{+}$ions. These phenomena can be classified as mechanochemico-vector effect. ${ }^{19)}$

\section{Conclusion}

Glass-ceramic Narpsio of a super sodium ion conductor was proved to be electrically polarized. The effects of the electrical polarization were obvious in morphologies of the overgrown crystals, while those on the growth rate were vague. Based on the SBF tests, glass-ceramic Narpsio was recognized to be osteoconductive regardless to the electrical polarization.

Acknowledgements This work was partly supported by a Grants-in-Aid from the Japan Society for the Promotion of Science (\#15360338) and the Mitsubishi Foundation.

\section{References}

1) Maksimov, B. A., Kharitonov, Y. A. and Belov, A. N. V., Sov. Phys. Dokl., Vol. 18, pp. 763-772 (1974).

2) Maksimov, B. A., Petrov, I. V., Rabenau, A. and Schulz, H., Solid State Ionics, Vol. 6, pp. 195-200 (1982).

3) Yamashita, K., Okura, S., Umegaki, T. and Kanazawa, T., Solid State Ionics, Vol. 26, pp. 279-286 (1988).

4) Yamashita, K., Nojiri, T., Umegaki, T. and Kanazawa, T., Solid State Ionics, Vol. 35, pp. 299-306 (1989).

5) Yamashita, K., Tanaka, M. and Umegaki, T., Solid State Ionics, Vol. 58, pp. 231-236 (1992)

6) Okura, T., Inami, Y., Monma, H., Nakamura, S. and Yamashita, K., Solid State Ionics, Vol. 154-155, pp. 361-366 (2002).

7) Yamashita, K., Nojiri, T., Umegaki, T. and Kanazawa, T., Solid State Ionics, Vol. 40/41, pp. 48-52 (1990).

8) Yamashita, K., Umegaki, T., Tanaka, M. and Nojiri, T., J. Electrochem. Soc., Vol. 143, pp. 2180-2186 (1996). 
9) Yamashita, K., Oikawa, N. and Umegaki, T., Chem. Mater., Vol. 8, pp. 2697-2700 (1996).

10) Nakamura, S., Takeda, H. and Yamashita, K., J. Appl. Phys., Vol. 89, pp. 5386-5392 (2001).

11) Kobayashi, T., Nakamura, S. and Yamashita, K., J. Biomed. Mater. Res., Vol. 57, pp. 477-484 (2001).

12) Nakamura, S., Kobayashi, T. and Yamashita, K., J. Biomed. Mater. Res., Vol. 61, pp. 593-599 (2002).

13) Nakamura, S., Kobayashi, T. and Yamashita, K., J. Biomed. Mater. Res., Vol. 68A, pp. 90-94 (2004).

14) Lavergne, C. and Lacabanne, C., IEEE Electr. Insul. Mag.,
Vol. 9, pp. 5-21 (1993).

15) Kokubo, T., Ito, S., Huang, Z., Hayashi, T. and Sakka, S., $J$ Biomed. Mater. Res., Vol. 24, pp. 331-343 (1990).

16) Ueshima, M., Nakamura, S. and Yamashita, K., Adv. Mater., Vol. 14, pp. 591-595 (2002).

17) Obata, A., Nakamura, S. and Yamashita, K., Biomaterials, Vol. 25, pp. 5163-5169 (2004).

18) Obata, A., Nakamura, S., Moriyoshi, Y. and Yamashita, K., J. Biomed. Mater. Res., Vol. 67A, pp. 413-420 (2003).

19) Yamashita, K. and Nakamura, S., J. Ceram. Soc. Japan, Vol. 113, pp. 1-9 (2005). 